\title{
Association of recent exposure to ambient metals on fractional exhaled nitric oxide in 9-11 year old inner-city children ${ }^{\text {in }}$
}

\author{
Maria José Rosa ${ }^{a}$, Matthew S. Perzanowski ${ }^{a}$, Adnan Divjan ${ }^{a}$, Steven N. Chillrud ${ }^{\mathrm{b}}$, Lori Hoepner ${ }^{\mathrm{a}}$, \\ Hanjie Zhang ${ }^{\mathrm{c}}$, Robert Ridder ${ }^{\mathrm{c}}$, Frederica P. Perera ${ }^{\mathrm{a}}$, Rachel L. Miller ${ }^{\mathrm{a}, \mathrm{c}, \mathrm{d}, *}$ \\ a Department of Environmental Health Sciences, Mailman School of Public Health, Columbia University, New York, NY, United States \\ ${ }^{\mathrm{b}}$ Lamont-Doherty Earth Observatory, Columbia University, Palisades, NY, United States \\ ' Division of Pulmonary, Allergy, Critical Care Medicine, Department of Medicine, Columbia University College of Physicians and Surgeons, New York, NY, United States \\ ${ }^{\mathrm{d}}$ Division of Pediatric Allergy, Immunology, and Rheumatology, Department of Pediatrics, Columbia University College of Physicians and Surgeons, New York, NY, United States
}

\section{A R T I C L E I N F O}

\section{Article history:}

Received 8 October 2013

Revised 16 May 2014

Available online 27 May 2014

\section{Keywords:}

Alveolar NO

Ambient metals

Asthma

Seroatopy

Bronchial flux

FENO

\begin{abstract}
A B S T R A C T
Exposure to ambient metals in urban environments has been associated with wheeze, and emergency room visits and hospitalizations due to respiratory illness. However, the effect of ambient metals exposure on airway inflammation, and how these associations may be modified by seroatopy, has not been determined. Fractional exhaled nitric oxide (FENO) is a reliable proxy marker of airway inflammation. We hypothesized that recent ambient concentrations of $\mathrm{Ni}, \mathrm{V}, \mathrm{Zn}$ and $\mathrm{Fe}$ would be associated differentially with proximal and distal fractions of exhaled NO, and that these associations would be modified by seroatopy. As part of the Columbia Center for Children's Environmental Health (CCCEH) birth cohort study, 9-11 year old children $(n=192)$ were evaluated. Ambient measures of Ni, V, Zn and Fe were obtained from a local central monitoring site and averaged over 9 days based on three $24 \mathrm{~h}$ measures every third day. Fractional exhaled nitric oxide (FENO) samples were obtained at constant flows of 50 $\left(\mathrm{FENO}_{50}\right), 83$ and $100 \mathrm{~mL} / \mathrm{s}$, and used to determine surrogate measures for proximal (JNO) and alveolar (Calv) inflammation. Seroatopy was determined by specific IgE at age 7. Data were analyzed using multivariable linear regression. Ambient $\mathrm{V}$ and $\mathrm{Fe}$ concentrations were associated positively with $\mathrm{FENO}_{50}$ $(p=0.018, p=0.027)$. Ambient Fe was associated positively with JNO $(p=0.017)$. Ambient Ni and V concentrations were associated positively with Calv $(p=0.004, p=0.018$, respectively). A stronger association of $\mathrm{Ni}$ concentrations with Calv was observed among the children with seroatopy. These results suggest that ambient metals are associated differentially with different fractions of FENO production, and this relationship may be modified by seroatopy.
\end{abstract}

(c) 2014 Elsevier Inc. All rights reserved.
Abbreviations: Calv, alveolar NO concentration; FENO, fractional exhaled nitric oxide; $\mathrm{FENO}_{50}$, fractional exhaled nitric oxide collected at $50 \mathrm{~mL} / \mathrm{s}$; JNO, bronchial flux; $\mathrm{PM}_{2.5}$, particulate matter $<2.5$ microns in diameter.

This work was performed at Columbia University.This work was supported by P50ES015905, 5P01ES09600/EPA RD-83214101, R01 ES008977, R01ES014393, P30ES09089, Bauman Family Foundation, Gladys \& Roland Harriman Foundation, New York Community Trust, Educational Foundation of America, The New York Times Company Foundation, Horace W. Goldsmith Foundation, The John Merck Fund, Johnson Family Foundation, The Marisla Foundation and Trustees of the Blanchette Hooker Rockefeller Fund.

* Corresponding author at: Division of Pulmonary, Allergy, Critical Care Medicine, Department of Medicine, Columbia University College of Physicians and Surgeons, PH8E-101, 630W. 168th St, New York, NY 10032, United States. Fax: +1 (212) 305 2277.

E-mail addresses: maria.rosa@mssm.edu (M.J. Rosa), mp2217@columbia.edu (M.S. Perzanowski), ad708@columbia.edu(A. Divjan),chilli@ldeo.columbia.edu (S.N. Chillrud), hoepner@nyspi.columbia.edu (L. Hoepner), hz2243@columbia.edu (H. Zhang),rmr2161@columbia.edu (R. Ridder), fpp1@columbia.edu (F.P. Perera), rlm14@columbia.edu (R.L. Miller).

\section{Introduction}

Exposure to particulate matter $<2.5$ microns in diameter $\left(\mathrm{PM}_{2.5}\right)$ has been associated with asthma development and acute exacerbations of symptoms [1,2]. The U.S. Environmental Protection Agency (EPA) currently utilizes particle diameter to establish mass-based standards for air quality regulation of fine inhalable particles that comprise $\mathrm{PM}_{2.5}$. However, $\mathrm{PM}_{2.5}$ consists of complex mixture that includes metals, organic compounds, sulfates and nitrates among other compounds and this composition may vary temporally, spatially and by source [3]. Mass-based standards fail to account for varying compositions and their differential effects on respiratory health. Therefore, it is important to understand which particular compounds may be associated with increased toxicity.

Despite growing research on some of the components, including polycyclic aromatic hydrocarbons (PAH) and elemental carbon (EC) 
[4,5], few studies have focused on the contribution of ambient transition metals. In New York City (NYC), a large number of apartment buildings burn residual oil for heating, and the burning is the major source of ambient nickel (Ni) and vanadium $(\mathrm{V})$ in $\mathrm{PM}_{2.5}$ [6]. $\mathrm{Ni}$ also is emitted during smelting processes, alloy production and other industrial activities [7]. Motor vehicle emissions are drivers of ambient zinc ( $\mathrm{Zn}$ ) and to a lesser extent $\mathrm{Ni}$ and $\mathrm{V}$ concentrations [8]. Additionally, burning of other fossil fuels such as coal and petroleum coke, used in electrical power generation, releases soot and fly ash containing V [9]. Sources of ambient iron (Fe) in $\mathrm{PM}_{2.5}$ include road dust, oil combustion, and re-suspended soils $[8,10]$. These outdoor sources have been shown to penetrate indoors and contribute to inside ambient levels and even greater exposures for children [11]. Also, young children are especially susceptible to the effects of airborne pollution due to faster breathing patters that can lead to greater inhalation of PM into their developing lungs [12]. Given the variety in sources of exposure, it is important to understand how the individual airborne metals impact respiratory health.

Emerging evidence implicates several individual airborne metals and adverse respiratory effects. For example, central site levels of ambient $\mathrm{Zn}$ were associated with increases in emergency department (ED) visits and hospitalizations for asthma in a pediatric population in Baltimore [13]. Risk of cardiovascular and respiratory hospitalizations following short-term exposure to $\mathrm{PM}_{2.5}$, was higher in US counties with higher measured levels of $\mathrm{Ni}$ and $\mathrm{V}$ [14]. In California, increased ambient levels of Fe and Zn were associated with respiratory hospital admissions among children [15]. In NYC, ambient measures of $\mathrm{Ni}$ and $\mathrm{V}$ were associated with increased probability of wheeze, and higher levels of Fe were associated with cough at age 24 months in our Columbia Center for Children's Environmental Health (CCCEH) birth cohort [16].

Measurement of fractional exhaled nitric oxide (FENO), typically collected at $50 \mathrm{~mL} / \mathrm{s}$ as recommend by the American Thoracic Society (ATS) [17], provides an indication of airway inflammation that has been associated with asthma development [18] and exacerbations [19]. Higher levels have been detected following recent environmental exposures [20]. Personal and central site exposure to both $\mathrm{EC}$ and $\mathrm{NO}_{2}$ was associated with increments in FENO in California school children [21]. Another study in California school children found significant associations between ambient cumulative lagged averages over 1-8 days of $\mathrm{PM}_{2.5}$ and elevated levels of FENO [22]. Furthermore, these associations have been shown to vary by atopy. In a study of French children, levels of $\mathrm{PM}_{2.5}$, formaldehyde and acetaldehyde measured in schools were associated positively with FENO, and these associations were stronger among children with atopy, defined as at least one positive skin prick test to an aeroallergen [23]. In contrast, in NYC, domestic levels of black carbon (BC)/soot, a tracer of combustion emissions of residual fuel oil and traffic, were associated with higher FENO levels among children without seroatopy, with seroatopy defined as any specific $\mathrm{IgE} \geqslant 0.35 \mathrm{IU} / \mathrm{mL}$ to common aeroallergens [24].

Furthermore, the collection of FENO at multiple flow rates allows the apportionment of NO derived from the alveolar/peripheral and bronchial/central compartments through the use of a mathematical model [25]. This method has proved useful in identifying sources of NO production in subjects with different asthma severity [26]. In our cohort we found that bronchial NO (JNO) was associated with seroatopy while alveolar NO (Calv) was associated only with report of current wheeze [27]. Furthermore, this method has been used to the determine the association between ambient exposures such as environmental tobacco smoke (ETS) and airway inflammation [28]. For example, non-asthmatic silica-exposed workers in Finland had significantly higher alveolar NO (Calv), but not bronchial NO (JNO), compared to healthy volunteers after adjustment for age, body mass index (BMI) and smoking history [29].

Previously, it has been shown that the association between $\mathrm{PM}_{10}, \mathrm{PM}_{2.5}, \mathrm{O}_{3}$ and $\mathrm{NO} x$ and FENO may vary by several day lag time $[21,22,30]$. Berhane et al. reported significant associations between cumulative lagged averages over 1-8 days between $\mathrm{PM}_{2.5}$ and FENO. In order to account for weekly pollutant and weather patterns $[31,32]$ and due to results from preliminary analyses, we sought to characterize the association between 9 day averages of airborne ambient metal concentrations (based on three $24 \mathrm{~h}$ measurements each 3rd day for $\mathrm{Ni}, \mathrm{V}, \mathrm{Zn}$ and $\mathrm{Fe}$ ) on $\mathrm{NO}$ derived from alveolar and bronchial compartments measured from children aged 9-11 years enrolled in the CCCEH birth cohort in NYC. Given previously observed differential associations between proximal and distal fractions of NO in our cohort, we hypothesized that airborne concentrations of $\mathrm{Ni}, \mathrm{V}, \mathrm{Zn}$ and Fe would be associated differentially with proximal and distal fractions of NO. We also hypothesized that the association between ambient metal exposure and FENO parameters would be modified by seroatopy.

\section{Material and methods}

\subsection{Study population}

Participants were enrolled in the prospective birth cohort study ( $n=727$ ) conducted by the CCCEH and enrollment has been described previously [4]. Non-smoking, healthy pregnant women aged 18-35, who self-identified as African-American or Dominican and were living in Northern Manhattan and the South Bronx were enrolled. Of the 727 fully enrolled participants, 225 (30.9\%) had at least one valid set of multiple flow measures from which distal and proximal fractions could be calculated, at ages 9 or 11 . Of those 225 children, 192 (85.3\%) had corresponding ambient metal concentrations collected within nine days of the FENO collection (Table 1). Only children that resided within the study catchment area at the time of collection were included in the analyses. Children were assigned their mother's reported race/ethnicity. Informed consent was obtained in accordance with the Institutional Review Board at Columbia University. Socio-demographic information was obtained from baseline (prenatal) questionnaires. Specific IgE

Table 1

Selected cohort characteristics.

\begin{tabular}{llll}
\hline Characteristic & Included $n=192$ & Excluded $^{\dagger} n=539$ & $p$-Value \\
\hline Mother's age $^{\mathrm{a}}$ & $24(21-29)$ & $24(21-29)$ & 0.395 \\
Child's age $^{\mathrm{a}}$ & $9.0(9.0-9.2)$ & $8.1(5.8,10)$ & $<0.001$ \\
Child's race/ethnicity $_{\text {African American (\%) }}$ & 48 & & $<0.001$ \\
Dominican (\%) $_{\text {Maternal education }}^{\mathrm{b}}(\%)$ & 52 & 30 & \\
Maternal asthmac (\%) $_{\text {Child's sex (\% male) }}$ & 28 & 70 & 0.903 \\
Prenatal ETS $^{\mathrm{d}}$ exposure (\%) & 41 & 64 & 0.295 \\
\hline
\end{tabular}

a Median (25th-75th percentiles), Mann Whitney $U$ test

b Mother completed high school, General Educational Development (GED) test or greater.

c Mother reported asthma in prenatal or 3 month questionnaire.

d Prenatal ETS exposure defined as maternal or cord blood cotinine level $\geqslant 15$ $\mathrm{ng} / \mathrm{mL}$ or report of smoker in the home from prenatal questionnaire. \#Differences in categorical variables tested using Pearson Chi-Square.

$\dagger 333 / 727$ (45.8\%) children excluded because they had not yet reached at least age 9 by June $24^{\text {th }}, 2010$, the last day of available central site monitoring data.

$169 / 394$ (42.9\%) children were excluded because they did not have available FENO data.

$3 / 225$ (1.3\%) were excluded due to ambient NO levels greater than $100 \mathrm{ppb}$ and the potential for contamination from ambient NO.30/222 (13.5\%) were excluded because they resided outside of study catchment area. 
against cockroach, Dermatophagoides farinae, mouse, dog, cat, mold, tree mix, grass and ragweed were measured by Immunocap (Phadia, Uppsala, Sweden) in sera collected at age $7(n=171)$ as previously described [33].

\subsection{Measures of exposure}

Twenty-four hour average $\mathrm{PM}_{2.5}$ concentrations were collected daily using a filter based method (instrument: Rupprecht \& Patashnick TEOM 1400ab and 2025 Partisol) by the New York State Department of Environmental Conservation (DEC) in accordance to EPA guidelines. Average $24 \mathrm{~h}$ ambient concentrations of $\mathrm{PM}_{2.5}$ fractions of $\mathrm{Ni}, \mathrm{V}, \mathrm{Zn}$ and Fe were measured every third day using a Rupprecht \& Patshnick 2300 Partisol and the most complete, validated dataset from the Intermediate School 52 (IS52) in Bronx county, was requested. This site was picked due to the availability of metals data and its location within the study catchment area of Northern Manhattan and the South Bronx [34,35] Given the limited number of EC measurements available, EC was excluded as a potential predictor. In these analyses the available data spanned from January 2008 to June 18, 2010 until the monitoring site was shut down.

\subsection{FENO parameters: $\mathrm{FENO}_{50}$, JNO and Calv}

FENO was collected at ages 9 or 11 years utilizing a previously modified offline NO collection method [36]. Children were instructed to inhale through an NO scrubber. FENO samples were obtained in duplicate at 50 and $100 \mathrm{~mL} / \mathrm{s}$ and in triplicate at $83 \mathrm{~mL} / \mathrm{s}$. $\mathrm{FENO}_{50}$ was defined as FENO collected at $50 \mathrm{~mL} / \mathrm{s}$. Bronchial flux (JNO) and alveolar NO (Calv) were calculated using a previously described modified Hogman method that utilized FENO collected at these 3 different flow rates [27,37]. Even though the Hogman method utilizes higher flow rates, previously we described good correlations for both JNO and Calv using values calculated with the Hogman and the Pietropaoli methods [27]. JNO and Calv were defined as surrogate measures of NO emanating from 2 compartments described by the Hogman mathematical model, the proximal airway region and the alveolar region respectively.

\subsection{Statistical analyses}

Data were analyzed using linear regression. In order to examine the potential temporal variation in these associations, three different metal exposure assignments were modeled preliminarily. Because metals data were only collected every third day, the first model assigned exposure based on the closest available measurement, either same day as FeNO collection, one day or 2 days prior. However, this exposure assignment was problematic because the exposure lag time was not uniform for all participants. The second exposure assignment utilized the average of two measurements within 6 days of the FeNO collection and the third exposure assignment used the average of three measurements within 9 days of the FeNO collection. In these models, the metal measurements averaged had to be collected the day of or prior to the day of FeNO collection. The final model utilized the natural log of the average of three measurements 3 days apart because these models captured both weekday and weekend emissions, accounted for weekly weather and pollution cycles [31,32] and because they explained a greater amount of variance in FENO parameters than the other exposure assignments. Metal concentrations were log transformed due to a large amount of relative variation and to improve fit [38]. Exploratory analyses also were conducted for daily $\mathrm{PM}_{2.5}$ concentrations and 1-9 day lag day values. The outcomes of interest were $\mathrm{FENO}_{50}$, JNO and Calv. NO outcomes were found to be log normally distributed; therefore they were log transformed. Log transformations of outcome and predictor variables require $\beta$ coefficients be interpreted as percent increases.

During FENO collections, parents also were asked about whether the child had a cold or respiratory infection that day and about use of asthma medication, including current inhaled corticosteroid (ICS) use. Parents also were asked if the children had eaten anything within $2 \mathrm{~h}$ of the FENO collection. Multivariable models were adjusted for race/ethnicity, sex, cold/influenza season, report of current respiratory infection or cold, report of smoker in home, report of the child eating within $2 \mathrm{~h}$ of the FENO collection, distance to central site and ambient NO levels. Report of any recent ICS use was uncommon among the participants $(<10 \%)$ and only 5 children had report of ICS use the day of the FENO collection. Effect estimates did not vary significantly after exclusion of the children with report of ICS use; consequently these children were included in final analyses. NOx species (4-day lag) was included as a co-pollutant in all models due a previously seen association with FENO [30]. Distance to central site was examined as a potential covariate in multivariable models but its inclusion did not significantly change any of the effect estimates. Due to a high degree of correlation, Ni, V, and $\mathrm{Zn}$ were all analyzed in separate models. Fe was highly correlated with $\mathrm{V}$ and $\mathrm{Zn}$ but not with $\mathrm{Ni}$, so $\mathrm{Ni}$ and $\mathrm{Fe}$ also were examined in a co-pollutant model. Stratified analyses were carried out to determine if seroatopy, defined as any specific $\operatorname{IgE} \geqslant 0.35 \mathrm{IU} / \mathrm{mL}$ to cockroach, mouse, $D$. farinae, dog, cat, mold, tree, grass or ragweed at age 7 modified the association between ambient metals exposure and FENO parameters.

\section{Results}

\subsection{Characteristics of cohort and pollutant concentrations}

Demographic characteristics comparing CCCEH participants included in analyses $(n=192)$ with those excluded $(n=539)$ are shown (Table 1$)$. There were no significant differences in maternal education and maternal asthma. As expected, the median age of the excluded children was significantly lower because the majority had not reached age 9 . The percentage of males in the included cohort was slightly lower than those in the excluded cohort $(41 \%$ vs. $51 \%$ ). There was a significant difference in prenatal ETS exposure, with $42 \%$ in the included cohort and $32 \%$ in excluded cohort. Medians and 25th and 75th percentiles for averaged metal concentrations were as follows: Ni $5.25 \mathrm{ng} / \mathrm{m}^{3}$ [3.30, 9.96], V $2.33 \mathrm{ng} / \mathrm{m}^{3}$ $[1.35,3.43] \mathrm{Zn} 27.8 \mathrm{ng} / \mathrm{m}^{3}[22.1,41.7]$ and $\mathrm{Fe} 93.8 \mathrm{ng} / \mathrm{m}^{3}[74.6$, 116]. Correlation coefficients among V, $\mathrm{Zn}$ and Fe measures were all significant ( $p<0.01$, Table $\mathrm{S} 1$, online supplement). Ni measures correlated significantly with $\mathrm{V}$ and $\mathrm{Zn}$ but not with Fe. The median distance to the IS52 site was $3.93 \mathrm{~km}$ (25th-75th percentile 3.15$4.53 \mathrm{~km}) . \mathrm{FENO}_{50}$ correlated with both JNO and Calv $(p<0.01$, Table S2, online supplement) but JNO and Calv were not significantly correlated. The proportion of the selected children that reported wheeze in the past 12 months in response to the ISAAC questionnaire was $45 / 192$ (23.4\%). The proportion of children that had seroatopy was $78 / 171(45.6 \%)$.

\subsection{Associations between $\mathrm{Ni}, \mathrm{V}, \mathrm{Zn}$ and $\mathrm{Fe}$ and FENO parameters}

Previously, it has been shown that the association between $\mathrm{PM}_{10}, \mathrm{PM}_{2.5}, \mathrm{O}_{3}$ and $\mathrm{NO} x$ and FENO may vary by several day lag time $[22,30]$. In univariate models (Figure S1), V and Fe, but not $\mathrm{Ni}$ or $\mathrm{Zn}$, averaged over 9 days were significant predictors of FENO $_{50}(\beta=0.157,95 \% \mathrm{CI}[0.007,0.306]$ for $\mathrm{V}$ and $\beta=0.375,95 \%$ $\mathrm{CI}[0.053,0.696]$ for Fe). Of all 4 metals, only Fe was a significant 
Table 2

Adjusted $^{\mathrm{a}}$ linear regression models for associations between ambient pollutants and FENO measures $\beta(95 \% \mathrm{CI}){ }^{\mathrm{b}}$

\begin{tabular}{llll}
\hline Pollutant & $\mathrm{FENO}_{50}$ & $\mathrm{JNO}$ & Calv \\
\hline $\mathrm{Ni}$ & 0.105 & 0.038 & $0.256^{* *}$ \\
& $(-0.081,0.291)$ & $(-0.260,0.337)$ & $(0.085,0.426)$ \\
$\mathrm{V}$ & $0.198^{*}$ & 0.226 & $0.178^{*}$ \\
& $(0.046,0.350)$ & $(-0.014,0.467)$ & $(0.036,0.319)$ \\
$\mathrm{Zn}$ & -0.003 & -0.036 & -0.055 \\
& $(-0.237,0.231)$ & $(-0.407,0.336)$ & $(-0.275,0.165)$ \\
$\mathrm{Fe}$ & $0.406^{*}$ & $0.679^{*}$ & 0.047 \\
& $(0.060,0.751)$ & $(0.133,1.225)$ & $(-0.282,0.376)$ \\
\hline
\end{tabular}

a Models adjusted for race/ethnicity, sex, cold/flu season, report of cold or respiratory infection the day of the FENO collection, current environmental tobacco smoke exposure (report of a smoker in home), mean ambient NO levels, report of the child eating within $2 \mathrm{~h}$ of the FeNO collection, distance from child's home to central site and NOx 4-day lag.

b Log transformations of outcome and predictor variables require $\beta$ coefficients be interpreted as percent increases, i.e., a $1 \%$ increase in $\mathrm{Ni}$ is associated with a $25.6 \%$ increase in Calv.

$p<0.05$.

$p<0.01$

predictor of JNO levels $(\beta=0.607,95 \% \mathrm{CI}[0.074,1.139]) . \mathrm{Ni}$ $(\beta=0.185,95 \% \mathrm{CI}[0.035,0.335])$ and $\mathrm{V}(\beta=0.179,95 \% \mathrm{CI}[0.044$, $0.313])$, and not Fe, were significant predictors of Calv.

In multivariable models, after adjusting for covariates, $\mathrm{V}$ and $\mathrm{Fe}$ remained significant positive predictors of $\mathrm{FENO}_{50}(\beta=0.198,95 \%$ $\mathrm{CI}[0.046,0.350] ; \beta=0.406,95 \% \mathrm{CI}[0.060,0.751]$ for $\mathrm{V}$ and $\mathrm{Fe}$, respectively) (Table 2). Fe also remained a significant predictor of JNO $(\beta=0.679,95 \% \mathrm{CI}[0.133,1.225])$. Ni and V remained significant predictors of Calv $(\beta=0.256,95 \% \mathrm{CI}[0.085,0.426]$ for $\mathrm{Ni}$ and ( $\beta=0.178,95 \% \mathrm{CI}[0.036,0.319]$ for $\mathrm{V}) . \mathrm{PM}_{2.5}$ measures were examined as same day measurements and as 1-9 day lags. None of the $\mathrm{PM}_{2.5}$ measures were associated significantly with any FENO parameter nor changed any parameter estimates for the metals when included as a covariate in the multivariable model. Additionally, heating season was examined as a potential covariate to be included in the multivariable model instead of cold and flu season (which substantially overlaps with heating season), but inclusion of cold and flu season provided a better model fit (results not shown).

\subsection{Stratification by seroatopy}

Previous studies have shown a strong association between allergic sensitization and FENO levels [39-41]. Therefore, we proceeded to analyze a potential effect modification by seroatopy. Interaction terms for each metal and seroatopy were tested in the final multivariable model and a significant interaction was found between $\mathrm{Ni}$ and seroatopy. $\mathrm{Ni}$ appeared to have a stronger positive association on Calv among those children classified as seroatopic ( $\beta=0.438,95 \% \mathrm{CI}[0.119,0.758])$ than those who were not seroatopic $(\beta=0.058,95 \% \mathrm{CI}[-0.168,0.284])$. Fig. 1 shows a regression plot for the univariate $\mathrm{Ni}$ model stratified by seroatopic status. The association between $\mathrm{V}, \mathrm{Zn}, \mathrm{Fe}$ and FENO parameters did not appear to vary across strata of seroatopy (data now shown).

In order to examine if $\mathrm{Ni}$ and $\mathrm{Fe}$ were independent predictors of FENO parameters, a multivariable model that included both as predictors was tested. Results show that Ni and Fe appeared to act independently from one another. Fe remained a significant predictor of both $\mathrm{FENO}_{50}(\beta=0.380,95 \% \mathrm{CI}[0.022,0.738], p=0.038)$ and JNO ( $\beta=0.705,95 \% \mathrm{CI}[0.140,1.270], p=0.015)$ after inclusion of $\mathrm{Ni}$ in the model. Ni also remained a predictor of Calv $(\beta=0.266,95 \% \mathrm{CI}$ $[0.089,0.442], p=0.003$ ) after Fe was included in the multivariable model.
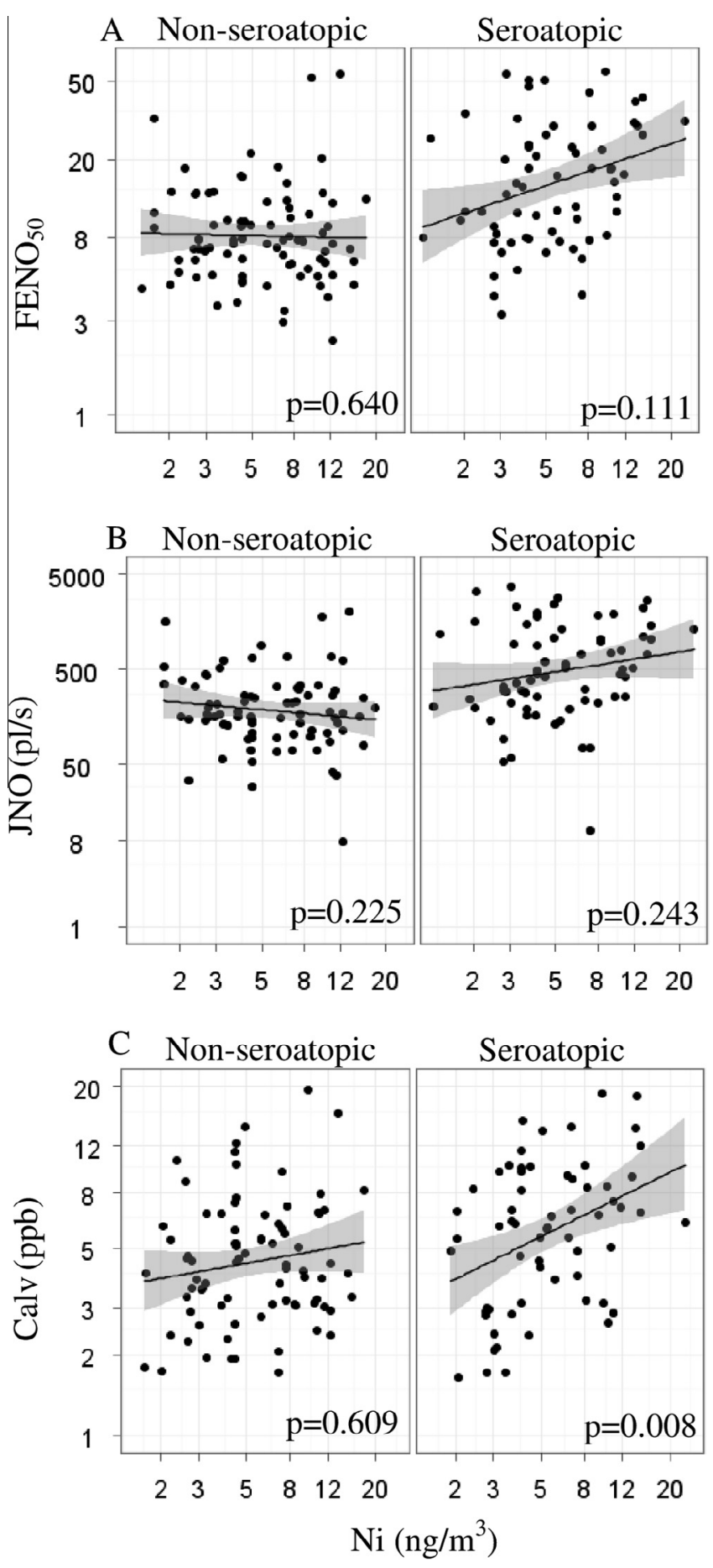

Fig. 1. Association between ambient $\mathrm{Ni}$ and FENO parameters modified by

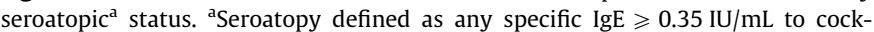
roach, mouse, D. farinae, dog, cat, mold, tree, grass or ragweed at age 7 . (A) Univariate linear regression model for Ni predicting $\mathrm{FENO}_{50}$ by seroatopic status. (B) Univariate linear regression model for Ni predicting JNO by seroatopic status. (C) Univariate linear regression model for Ni predicting Calv by seroatopic status. All $x$ and $y$ axes plotted on the natural log scale. P-values shown for multivariable models.

\section{Discussion}

The objective of this study was to characterize the association between measures of ambient $\mathrm{Ni}, \mathrm{V}, \mathrm{Zn}$ and Fe averaged over nine days and FENO parameters differentially representative of NO sources from proximal and distal airways in a cohort of children living in NYC. To our knowledge, this is the first paper to utilize 
the multiple flow method to determine such associations. We found that $\mathrm{Ni}$ and $\mathrm{V}$ concentrations were associated with increased levels of Calv, an indicator of distal airway inflammation, and additionally $\mathrm{V}$ concentrations were associated with increased levels of $\mathrm{FENO}_{50}$, presumed to indicate inflammation emanating from all compartments of the airways. Fe concentrations were associated with increased levels of $\mathrm{FENO}_{50}$ and JNO, and not Calv, indicating more proximal sources of inflammation. $\mathrm{Zn}$ concentrations were not associated with FENO. This study provides evidence that relatively short-term exposure to ambient transition metal fractions of $\mathrm{PM}_{2.5}$ may lead to an increase in airway inflammation, and that these metals may exert differential effects on the localized production of NO in the airways.

Associations between metal concentrations and FENO parameters were found when metal measures taken 3 days apart were averaged over longer time periods, which is consistent with previously published data on PM and EC [21,22]. A study of French schoolchildren found a significant association between 5-day average concentrations of $\mathrm{PM}_{2.5}$ measured in classrooms and increased NO in children with and without asthma [23]. In another study of California school children, the strongest associations were seen between cumulative lagged models of $\mathrm{PM}_{2.5}$ over $1-8$ days and FENO, rather than with models utilizing only the previous $24 \mathrm{~h}$ average of $\mathrm{PM}_{2.5}$ [22].

These results showed that $\mathrm{Ni}, \mathrm{V}$ and Fe exerted differential effects on fractions of exhaled NO, despite the significant correlations between outcome measures. Only a few studies have used the multiple flow method to partition NO contributions with mixed results. In a study of wood smoke exposure, healthy adult subjects who were exposed experimentally in a chamber to wood smoke for 4-h, had significantly elevated alveolar NO (Calv), but neither $\mathrm{FENO}_{50}$ nor bronchial NO (JNO) were increased [42]. Another study of healthy adult subjects showed that after $30 \mathrm{~min}$ of exercise in an area with high ambient UPM concentrations, alveolar NO decreased without change in bronchial NO [43]. Finally, in a study of adult asthmatic and healthy subjects, experimental exposure to nebulized UPM through a mouthpiece was not associated with any FENO parameter [44]. A possible explanation for the differential effects of $\mathrm{Ni}, \mathrm{V}$ and $\mathrm{Fe}$ on fractions of FENO is that each may affect the production of NO in the airways through a different pathway. There is some evidence that both iNOS and nNOS contribute to alveolar NO [45]. Another explanation might be the relative distribution of metals on particles of different sizes. In another study, $\mathrm{Ni}$ was found in fine, intermediate and coarse airborne particles while Fe was mainly found in particles with a diameter $>2.7 \mu \mathrm{m}$.[46] These findings suggest that Fe might not travel as small enough particles to reach the alveolar region and exert an effect on Calv levels.

We observed no association between $\mathrm{Zn}$ concentrations and any of the 3 FENO parameters. This finding was not entirely unexpected because there is evidence from rodents that intratracheal instillations of zinc sulfate induced pulmonary neutrophilic inflammation [47]. Previous studies have shown that $\mathrm{FENO}_{50}$ is elevated in the setting of eosinophilic, not neutrophilic, inflammation and correlated with sputum eosinophil counts [48]. There is also evidence that the addition of $\mathrm{Zn}$ to murine macrophages stimulated with interferon (IFN)- $\gamma$ and tumor necrosis factor (TNF)- $\alpha$ had no demonstrable effect on NO production [49].

There are only a few studies that help elucidate the mechanism through which ambient metal exposure leads to airway inflammation, and presumably subsequent airway disease and disease exacerbation. In vivo instillation of ambient particles rich in $\mathrm{Ni}, \mathrm{Zn}, \mathrm{Cd}$ and $\mathrm{Cu}$ increased secretion of pro-inflammatory cytokines interleukin (IL)-6 and TNF- $\alpha$ and generated elevated levels of oxidant radicals in bronchoalveolar lavage fluid (BAL) [50]. TNF- $\alpha$, in conjunction IFN- $\gamma$, may activate nuclear factor-kappa $B(N F-\kappa B)$ in tumorigenic mouse lung epithelial cells, leading to downstream activation of STAT1 and STAT3, ultimately responsible for iNOS expression [51]. Another potential mechanism through which these metals may lead to elevated NO levels involves the dysregulation of Fe homeostasis in the lungs. Inhaled $\mathrm{Ni}, \mathrm{V}$ and $\mathrm{Fe}$ may compete with the uptake of endogenous Fe, leading to elevated levels of available Fe and release of reactive oxygen species (ROS) $[52,53]$. NF- $\kappa B$ can be activated by oxidative stressors [54] and its activation has been shown to induce iNOS gene expression in mouse macrophages treated with lipopolysaccharide (LPS) [55].

The association between ambient measures of $\mathrm{Ni}$ and elevated Calv levels was strongest among seroatopic children. These results agree with previous research that found stronger associations between classroom levels of $\mathrm{PM}_{2.5}$, acetaldehyde and formaldehyde and elevated $\mathrm{FENO}_{50}$ levels among atopic children, suggesting atopic children may be more susceptible to the airway effects of these ambient pollutants [23]. These results also are consistent with a murine model of allergic asthma, where intratracheally administered UPM with high fractions of transition metals and metalloids, enhanced ovalbumin (OVA)-induced eosinophil recruitment in the alveoli and increased levels of eosinophilrelevant cytokines and chemokines, IL-5 and monocyte chemotactic protein-3 (MCP-3) in BAL [56]. However, the association for Ni and FeNO is not consistent with Cornell et al. (2012) that found that nonseroatopic children had a relationship between $\mathrm{BC}$ and $\mathrm{FENO}_{83}$ (FENO collected at $83 \mathrm{~mL} / \mathrm{s}$ ). This is also conflicting because one of the major sources of $\mathrm{BC}$ is residual fuel oil that is also a major source of Ni in NYC.

There are some limitations to this study. First, the use of central site measurements to assign exposure may not adequately reflect the spatial heterogeneity of individual exposure. However, a previous study found that 1 week average concentrations of $\mathrm{Ni}, \mathrm{V}$ and $\mathrm{Zn}$ measured at IS-52 site were highly correlated with the same metals measured at the New York Botanical Gardens site in Bronx county, also located within our study catchment area, approximately 3 miles away from the IS-52 site [16]. It is also possible that the ambient metals may be surrogates for other component of $\mathrm{PM}_{2.5}$. As seen in Table S1, the metals were highly correlated and we were unable to examine $\mathrm{Ni}$ and $\mathrm{V}$ in a co-pollutant model because of multi-collinearity, thus making it difficult to disentangle the individual effects of these metals on airway inflammation. Nevertheless, Ni and Fe were not strongly associated and we observed differential associations with FENO parameters when both metals were tested in the same model providing evidence of an independent effect. Another potential limitation is the fact that we did not control for cumulative exposure. FENO measures fluctuate daily within subjects, making it a more suitable biomarker for the study of responses to recent exposures. However, one-time measurements have been associated with environmental exposures and clinical outcomes. $\mathrm{PM}_{2.5}$ averaged over 5 days that was measured in school-yards and classrooms was associated with elevated levels of FENO in children living in France [57]. Domestic black measures averaged over 7 days were associated with increased levels of FENO in children without seroatopy living in NYC [24]. Elevated FENO levels measured in pre-school aged children were associated with increased risk of respiratory tract illness at one-year follow-up [58]. We also averaged metal concentrations over 9 days to assess lag effects after sub-acute exposure instead of fully evaluating lag effects of various durations to pinpoint the relevant time period, and instead of measuring cumulative exposures. Sample size was also a limitation that did not allow us to analyze other potential effect modifiers such as current wheeze and asthma diagnosis, nor to include other covariates such as heating season; however, all models were adjusted for cold and flu season that substantially overlaps with heating season. Another limitation was the cross-sectional nature of the analyses, given the daily fluctuation of FENO measures. 
Even though each lung compartment was not sampled separately in this study, the robustness of the mathematical model has been tested previously and the multiple flow method has been shown to reflect NO arising from different compartments [59]. In a previous study in the CCCEH cohort, we showed that seroatopy was closely related to JNO while report of wheeze in the past 12 months was only closely related to Calv [27]. A previous study also found elevated Calv levels among severe and uncontrolled asthmatic children when compared with corresponding healthy controls [60]. Distal lung inflammation also has been associated airway hyper-responsiveness, symptom exacerbation and tissue remodeling $[61,62]$. These studies suggest that the anatomical location of the NO source (i.e., distal vs. proximal airways) is relevant and consequently Calv may serve as a better predictor in the study of air pollution-induced exacerbations.

\section{Conclusions}

The associations between recent concentrations of airborne $\mathrm{Ni}$, $\mathrm{V}$ and Fe and increased levels of NO suggest that these metal fractions of $\mathrm{PM}_{2.5}$ lead to airway inflammation in the proximal and distal regions of the lungs. Our findings provide a better understanding of how different inhaled metals contribute to airway inflammation that may consequently lead to asthma exacerbation. The use of mass-based standards of fine particulate matter in air quality regulation by the EPA may not be sufficient to protect children from the immunotoxic effects of transition metals found in PM. Knowledge of the differential effects of different pollutants may lead to more targeted interventions directed at their sources i.e., switching to cleaner oils or natural gas for heating and setting better traffic emission standards.

\section{Acknowledgments}

The authors would like to thank the participating mothers and children. This work would not have been possible without the hard work and dedication of the research workers and field technicians.

\section{Appendix A. Supplementary data}

Supplementary data associated with this article can be found, in the online version, at http://dx.doi.org/10.1016/j.niox.2014.05.008.

\section{References}

[1] V. Morgenstern, A. Zutavern, J. Cyrys, I. Brockow, S. Koletzko, U. Kramer, H. Behrendt, O. Herbarth, A. von Berg, C.P. Bauer, H.E. Wichmann, J. Heinrich, Atopic diseases, allergic sensitization, and exposure to traffic-related air pollution in children, Am. J. Respir. Crit. Care Med. 177 (2008) 1331-1337.

[2] R. McConnell, K. Berhane, L. Yao, M. Jerrett, F. Lurmann, F. Gilliland, N. Künzli, J. Gauderman, E. Avol, D. Thomas, J. Peters, Traffic, susceptibility, and childhood asthma, Environ. Health Perspect. 114 (2006) 766-772.

[3] M.L. Bell, F. Dominici, K. Ebisu, S.L. Zeger, J.M. Samet, Spatial and temporal variation in $\operatorname{PM}(2.5)$ chemical composition in the United States for health effects studies, Environ. Health Perspect. 115 (2007) 989-995.

[4] R.L. Miller, R. Garfinkel, M. Horton, D. Camann, F.P. Perera, R.M. Whyatt, P.L. Kinney, Polycyclic aromatic hydrocarbons, environmental tobacco smoke, and respiratory symptoms in an inner-city birth cohort, Chest 126 (2004) 1071 1078.

[5] K.H. Jung, S.I. Hsu, B. Yan, K. Moors, S.N. Chillrud, J. Ross, S. Wang, M.S. Perzanowski, P.L. Kinney, R.M. Whyatt, F.P. Perera, R.L. Miller, Childhood exposure to fine particulate matter and black carbon and the development of new wheeze between ages 5 and 7 in an urban prospective cohort, Environ. Int 45 (2012) 44-50.

[6] R.E. Peltier, S.I. Hsu, R. Lall, M. Lippmann, Residual oil combustion: a major source of airborne nickel in New York City, J. Expo. Sci. Environ. Epidemiol. 19 (2009) 603-612.

[7] I.P.o.C.S. (IPCS), Environmental Health Criteria Series \#108: Nickel, World Health Organization, Geneva, Switzerland, 1991.

[8] Z. Li, P.K. Hopke, L. Husain, S. Qureshi, V.A. Dutkiewicz, J.J. Schwab, F. Drewnick, K.L. Demerjian, Sources of fine particle composition in New York City, Atmos. Environ. 38 (2004) 6521-6529.
[9] M. Costigan, R. Cary, S. Dobson, World Health Organization., International Labour Organisation., United Nations Environment Programme., International Program on Chemical Safety., Inter-Organization Programme for the Sound Management of Chemicals., Vanadium pentoxide and other inorganic vanadium compounds, World Health Organization, Geneva, 2001.

[10] S.N. Chillrud, D. Epstein, J.M. Ross, S.N. Sax, D. Pederson, J.D. Spengler, P.L. Kinney, Elevated airborne exposures of teenagers to manganese, chromium, and iron from steel dust and New York City's subway system, Environ. Sci. Technol. 38 (2004) 732-737.

[11] P.L. Kinney, S.N. Chillrud, S. Ramstrom, J. Ross, J.D. Spengler, Exposures to multiple air toxics in New York City, Environ. Health Perspect. 110 (Suppl. 4) (2002) 539-546

[12] J.D. Sacks, L.W. Stanek, T.J. Luben, D.O. Johns, B.J. Buckley, J.S. Brown, M. Ross, Particulate matter-induced health effects: who is susceptible?, Environ Health Perspect. 119 (2011) 446-454.

[13] J.M. Hirshon, M. Shardell, S. Alles, J.L. Powell, K. Squibb, J. Ondov, C.J. Blaisdell, Elevated ambient air zinc increases pediatric asthma morbidity, Environ. Health Perspect. 116 (2008) 826-831.

[14] M.L. Bell, K. Ebisu, R.D. Peng, J.M. Samet, F. Dominici, Hospital admissions and chemical composition of fine particle air pollution, Am. J. Respir. Crit. Care Med. 179 (2009) 1115-1120.

[15] B. Ostro, L. Roth, B. Malig, M. Marty, The effects of fine particle components on respiratory hospital admissions in children, Environ. Health Perspect. 117 (2009) 475-480.

[16] M.M. Patel, L. Hoepner, R. Garfinkel, S. Chillrud, A. Reyes, J.W. Quinn, F. Perera, R.L. Miller, Ambient metals, elemental carbon, and wheeze and cough in New York City children through 24 months of age, Am. J. Respir. Crit. Care Med. 180 (2009) 1107-1113.

[17] R.A. Dweik, P.B. Boggs, S.C. Erzurum, C.G. Irvin, M.W. Leigh, J.O. Lundberg, A.C. Olin, A.L. Plummer, D.R. Taylor, An official ATS clinical practice guideline: interpretation of exhaled nitric oxide levels (FENO) for clinical applications, Am. J. Respir. Crit. Care Med. 184 (2011) 602-615.

[18] D. Caudri, A.H. Wijga, M.O. Hoekstra, M. Kerkhof, G.H. Koppelman, B. Brunekreef, H.A. Smit, J.C. de Jongste, Prediction of asthma in symptomatic preschool children using exhaled nitric oxide, Rint and specific IgE, Thorax 65 (2010) 801-807.

[19] R.J. van der Valk, E. Baraldi, G. Stern, U. Frey, J.C. de Jongste, Daily exhaled nitric oxide measurements and asthma exacerbations in children, Allergy 67 (2012) 265-271.

[20] A.C. Just, R.M. Whyatt, R.L. Miller, A.G. Rundle, O Chen, A.M. Calafat, A. Divjan, M.J. Rosa, H. Zhang, F.P. Perera, I.F. Goldstein, M.S. Perzanowski, Children's urinary phthalate metabolites and fractional exhaled nitric oxide in an urban cohort, Am. J. Respir. Crit. Care Med. 186 (2012) 830-837.

[21] R.J. Delfino, N. Staimer, D. Gillen, T. Tjoa, C. Sioutas, K. Fung, S.C. George, M.T. Kleinman, Personal and ambient air pollution is associated with increased exhaled nitric oxide in children with asthma, Environ. Health Perspect. 114 (2006) 1736-1743.

[22] K. Berhane, Y. Zhang, W.S. Linn, E.B. Rappaport, T.M. Bastain, M.T. Salam, T. Islam, F. Lurmann, F.D. Gilliland, The effect of ambient air pollution on exhaled nitric oxide in the children's health study, Eur. Respir. J. 37 (2011) 1029-1036.

[23] M. Flamant-Hulin, D. Caillaud, P. Sacco, C. Pénard-Morand, I. Annesi-Maesano, Air pollution and increased levels of fractional exhaled nitric oxide in children with no history of airway damage, J. Toxicol. Environ. Health A 73 (2009) 272283.

[24] A.G. Cornell, S.N. Chillrud, R.B. Mellins, L.M. Acosta, R.L. Miller, J.W. Quinn, B. Yan, A. Divjan, O.E. Olmedo, S. Lopez-Pintado, P.L. Kinney, F.P. Perera, J.S. Jacobson, I.F. Goldstein, A.G. Rundle, M.S. Perzanowski, Domestic airborne black carbon and exhaled nitric oxide in children in NYC, J. Expo. Sci. Environ. Epidemiol. 22 (2012) 258-266.

[25] S.C. George, Modeling pulmonary nitric oxide exchange, J. Appl. Physiol. 96 (2003) 831-839.

[26] C. Brindicci, K. Ito, P.J. Barnes, S.A. Kharitonov, Differential flow analysis of exhaled nitric oxide in patients with asthma of differing severity, Chest 131 (2007) 1353-1362.

[27] M.J. Rosa, A. Divjan, L. Hoepner, B.J. Sheares, D. Diaz, K. Gauvey-Kern, F.P. Perera, R.L. Miller, M.S. Perzanowski, Fractional exhaled nitric oxide exchange parameters among 9-year-old inner-city children, Pediatr. Pulmonol. 46 (2011) 83-91.

[28] A. Malinovschi, C. Janson, T. Holmkvist, D. Norback, P. Merilainen, M. Hogman, Effect of smoking on exhaled nitric oxide and flow-independent nitric oxide exchange parameters, Eur. Respir. J. 28 (2006) 339-345.

[29] R. Sauni, P. Oksa, L. Lehtimaki, P. Toivio, P. Palmroos, R. Nieminen, E. Moilanen, J. Uitti, Increased alveolar nitric oxide and systemic inflammation markers in silica-exposed workers, Occup. Environ. Med. 69 (2012) 256-260.

[30] B. Obeng, Short term effects of regional air pollution on fractional exhaled nitric oxide in children of New York City, Am. J. Respir. Crit. Care Med. 181 (2010).

[31] R.S. Cerveny, R.C. Balling, Weekly cycles of air pollutants, precipitation and tropical cyclones in the coastal NW Atlantic region, Nature 394 (1998) 561563.

[32] Ws. Clevelan, T.E. Graedel, B. Kleiner, J.L. Warner, Sunday and workday variations in photochemical air-pollutants in New-Jersey and New-York, Science 186 (1974) 1037-1038.

[33] K.M. Donohue, U. Al-alem, M.S. Perzanowski, G.L. Chew, A. Johnson, A. Divjan, E.A. Kelvin, L.A. Hoepner, F.P. Perera, R.L. Miller, Anti-cockroach and anti- 
mouse IgE are associated with early wheeze and atopy in an inner-city birth cohort, J. Allergy Clin. Immunol. 122 (2008) 914-920.

[34] K.H. Jung, M.M. Patel, K. Moors, P.L. Kinney, S.N. Chillrud, R. Whyatt, L. Hoepner, R. Garfinkel, B. Yan, J. Ross, D. Camann, F.P. Perera, R.L. Miller, Effects of heating season on residential indoor and outdoor polycyclic aromatic hydrocarbons, black carbon, and particulate matter in an urban birth cohort, Atmos. Environ. 44 (2010) (1994) 4545-4552.

[35] M.K. Horton, J.B. Jacobson, W. McKelvey, D. Holmes, B. Fincher, A. Quantano, B.P. Diaz, F. Shabbazz, P. Shepard, A. Rundle, R.M. Whyatt, Characterization of residential pest control products used in inner city communities in New York City, J. Expo. Sci. Environ. Epidemiol. 21 (2011) 291-301.

[36] M.S. Perzanowski, M.J. Rosa, A. Divjan, A. Johnson, J.S. Jacobson, R.L. Miller Modifications improve an offline exhaled nitric oxide collection device for use with young children, J. Allergy Clin. Immunol. 122 (2008) 213 (author reply 214).

[37] M. Hogman, T. Holmkvist, T. Wegener, M. Emtner, M. Andersson, H. Hedenstrom, P. Merilainen, Extended NO analysis applied to patients with COPD, allergic asthma and allergic rhinitis, Respir. Med. 96 (2002) 24-30.

[38] A. Gelman, J. Hill, Data Analysis using Regression and Multilevel/Hierarchical Models, Cambridge University Press, Cambridge, New York, 2007.

[39] D. Ludviksdottir, C. Janson, M. Hogman, H. Hedenstrom, E. Bjornsson, G. Boman, Exhaled nitric oxide and its relationship to airway responsiveness and atopy in asthma, BHR-study group, Respir. Med. 93 (1999) 552-556.

[40] S.L. Nordvall, C. Janson, P. Kalm-Stephens, T. Foucard, K. Toren, K. Alving, Exhaled nitric oxide in a population-based study of asthma and allergy in schoolchildren, Allergy 60 (2005) 469-475.

[41] A. Patelis, M. Gunnbjornsdottir, A. Malinovschi, P. Matsson, A. Onell, M. Hogman, K. Alving, C. Janson, Population-based study of multiplexed IgE sensitization in relation to asthma, exhaled nitric oxide, and bronchial responsiveness, J. Allergy Clin. Immunol. 130 (2012) 397-402. e2.

[42] L. Barregard, G. Sallsten, L. Andersson, A.C. Almstrand, P. Gustafson, M. Andersson, A.C. Olin, Experimental exposure to wood smoke: effects on airway inflammation and oxidative stress, Occup. Environ. Med. 65 (2008) 319-324.

[43] K.W. Rundell, J.B. Slee, R. Caviston, A.M. Hollenbach, Decreased lung function after inhalation of ultrafine and fine particulate matter during exercise is related to decreased total nitrate in exhaled breath condensate, Inhal. Toxicol. 20 (2008) 1-9.

[44] A.P. Pietropaoli, M.W. Frampton, R.W. Hyde, P.E. Morrow, G. Oberdorster, C. Cox, D.M. Speers, L.M. Frasier, D.C. Chalupa, L.S. Huang, M.J. Utell, Pulmonary function, diffusing capacity, and inflammation in healthy and asthmatic subjects exposed to ultrafine particles, Inhal. Toxicol. 16 (Suppl. 1) (2004) 5972.

[45] C. Brindicci, K. Ito, O. Torre, P.J. Barnes, S.A. Kharitonov, Effects of aminoguanidine, an inhibitor of inducible nitric oxide synthase, on nitric oxide production and its metabolites in healthy control subjects, healthy smokers, and COPD patients, Chest 135 (2009) 353-367.

[46] C. Samara, D. Voutsa, Size distribution of airborne particulate matter and associated heavy metals in the roadside environment, Chemosphere 59 (2005) 1197-1206.

[47] U.P. Kodavanti, M.C. Schladweiler, A.D. Ledbetter, R. Hauser, D.C. Christiani, J.M. Samet, J. McGee, J.H. Richards, D.L. Costa, Pulmonary and systemic effects of zinc-containing emission particles in three rat strains: multiple exposure scenarios, Toxicol. Sci. 70 (2002) 73-85.
48] F.N. Schleich, L. Seidel, J. Sele, M. Manise, V. Quaedvlieg, A. Michils, R. Louis, Exhaled nitric oxide thresholds associated with a sputum eosinophil count $>\mid$ $=3 \%$ in a cohort of unselected patients with asthma, Thorax 65 (2010) 10391044.

49] L. Tian, D.A. Lawrence, Metal-induced modulation of nitric oxide production in vitro by murine macrophages: lead, nickel, and cobalt utilize different mechanisms, Toxicol. Appl. Pharmacol. 141 (1996) 540-547.

[50] F. Schaumann, Metal-rich ambient particles (Particulate Matter2.5) cause airway inflammation in healthy subjects, Am. J. Respir. Crit. Care Med. 170 (2004) 898-903.

[51] A. Tyagi, C. Agarwal, L.D. Dwyer-Nield, R.P. Singh, A.M. Malkinson, R. Agarwal, Silibinin modulates TNF-alpha and IFN-gamma mediated signaling to regulate COX2 and iNOS expression in tumorigenic mouse lung epithelial LM2 cells, Mol. Carcinog. 51 (2012) 832-842.

[52] A.J. Ghio, M.D. Cohen, Disruption of iron homeostasis as a mechanism of biologic effect by ambient air pollution particles, Inhal. Toxicol. 17 (2005) 709716.

[53] C. Prophete, P. Maciejczyk, K. Salnikow, T. Gould, T. Larson, J. Koenig, P. Jaques, C. Sioutas, M. Lippmann, M. Cohen, Effects of select PM-associated metals on alveolar macrophage phosphorylated ERK1 and -2 and iNOS expression during ongoing alteration in iron homeostasis, J. Toxicol. Environ. Health A 69 (2006) 935-951.

[54] I. Rahman, W. MacNee, Role of transcription factors in inflammatory lung diseases, Thorax 53 (1998) 601-612.

[55] Q.W. Xie, Y. Kashiwabara, C. Nathan, Role of transcription factor NF-kappa B/ Rel in induction of nitric oxide synthase, J. Biol. Chem. 269 (1994) 4705-4708.

[56] M. He, T. Ichinose, S. Yoshida, M. Nishikawa, I. Mori, R. Yanagisawa, H. Takano, K. Inoue, G. Sun, T. Shibamoto, Urban particulate matter in Beijing, China, enhances allergen-induced murine lung eosinophilia, Inhal. Toxicol. 22 (2010) 709-718.

[57] M. Flamant-Hulin, D. Caillaud, P. Sacco, C. Penard-Morand, I. Annesi-Maesano Air pollution and increased levels of fractional exhaled nitric oxide in children with no history of airway damage, J. Toxicol. Environ. Health A Curr. Issues 73 (2010) 272-283.

[58] A. Beigelman, D.T. Mauger, B.R. Phillips, R.S. Zeiger, L.M. Taussig, R.C. Strunk, L.B. Bacharier, C.N.N.H.L. Blood, Effect of elevated exhaled nitric oxide levels on the risk of respiratory tract illness in preschool-aged children with moderateto-severe intermittent wheezing, Ann. Allergy Asthma Immunol. 103 (2009) $108-113$.

[59] S. Verbanck, Y. Kerckx, D. Schuermans, C. de Bisschop, H. Guenard, R. Naeije, W. Vincken, A. Van Muylem, The effect of posture-induced changes in peripheral nitric oxide uptake on exhaled nitric oxide, J. Appl. Physiol. 106 (2009) 1494-1498.

[60] E. Paraskakis, Measurement of bronchial and alveolar nitric oxide production in normal children and children with asthma, Am. J. Respir. Crit. Care Med. 174 (2006) 260-267.

[61] R.J. Martin, Therapeutic significance of distal airway inflammation in asthma, J. Allergy Clin. Immunol. 109 (2002) S447-S460.

[62] M. Kraft, J. Pak, R.J. Martin, D. Kaminsky, C.G. Irvin, Distal lung dysfunction at night in nocturnal asthma, Am. J. Respir. Crit. Care Med. 163 (2001) 15511556. 